\title{
SIGNIFICADO DA PRÁTICA ESPORTIVA DO VOLEIBOL: ESTUDO DE CASO COM IDOSOS'
}

\author{
Lucélia Justino Borges \\ Universidade Federal de Santa Catarina, Florianópolis, Santa Catarina, Brasil. \\ Marize Amorim Lopes \\ Universidade Federal de Santa Catarina, Florianópolis, Santa Catarina, Brasil.
}

Tânia R. Bertoldo Benedetti

Universidade Federal de Santa Catarina, Florianópolis, Santa Catarina, Brasil.

\begin{abstract}
Resumo
Objetivou-se analisar o significado e os motivos de adoção e permanência na prática esportiva do voleibol, por idosos de um programa de extensão universitária. Os dados foram obtidos por meio de análise documental, entrevista semiestruturada e questionário, sendo analisados e interpretados por meio da análise de conteúdo. Verificou-se que o significado do voleibol está atrelado à socialização; disposição e bem-estar; saúde. O gosto pela prática desse esporte foi o motivo mais citado para adoção e permanência dos idosos no programa. As categorias analisadas mostraram-se inter-relacionadas e atreladas à percepção dos benefícios físicos, psicológicos e sociais. Além disso, observou-se que os idosos deram um novo significado para o objetivo do esporte, e o jogo, como estratégia metodológica, mostrou-se fator motivador para o desenvolvimento do voleibol.
\end{abstract}

Palavras-chave: Voleibol. Idoso. Envelhecimento.

\section{Introdução}

O voleibol tem-se transformado em um esporte com grande participação popular no mundo, sendo o segundo esporte mais praticado no Brasil (CONFEDERAÇÃO BRASILEIRA DE VOLEIBOL - CBV, 2013a). A popularidade do voleibol cresceu nas últimas décadas e pode ser explicado, entre outros motivos, pelas conquistas das seleções brasileiras e pelo patrocínio de grandes empresas (CBV, 2013a).

A prática desse esporte ocorre tanto na forma recreativa quanto profissional (BOJIKIAN, 2005). A forma recreativa envolve todos os grupos etários, perdendo somente para o futebol (CBV, 2013a). Especificamente para a população idosa, tal prática é oferecida pelos projetos de extensão realizados nas Universidades, pelo Serviço Social do Comércio (SESC), pelos projetos municipais de atenção à pessoa idosa entre outros. Vale ressaltar que a prática de forma competitiva, que antes se restringia a adolescentes e adultos, atualmente tem atraído as pessoas idosas. Esse fato pode ser comprovado pelo aumento do número de participantes no Campeonato Brasileiro de Voleibol Master, sendo

\footnotetext{
${ }^{1} \mathrm{O}$ presente trabalho não contou com apoio financeiro para sua realização.
} 
que, em 2012, foram disponibilizadas inscrições em duas categorias para os homens (59 anos ou mais; 63 anos ou mais) e três categorias para as mulheres (59 anos ou mais; 63 anos ou mais; 70 anos ou mais) (CBV, 2013b).

Nesse contexto, o aumento do número de praticantes de voleibol e o aumento da expectativa de vida no Brasil podem ter contribuído para a maior participação de idosos nesse esporte. De um lado, observa-se que as melhores condições de vida e de saúde contribuem para a longevidade, possibilitando, assim, que ex-atletas envelheçam e continuem a praticar o esporte. Por outro, a longevidade tem proporcionado a inserção de pessoas em práticas esportivas após os 60 anos, uma vez que essas modalidades, em muitos casos, não faziam parte do cotidiano dessa geração envelhecida.

Os esportes, assim como as diferentes modalidades de atividades físicas disponibilizadas para os idosos, oportunizam a melhora de suas aptidões físicas, contribuindo para a manutenção e/ou melhora da capacidade funcional, prevenindo a dependência e a incapacidade física.

Entretanto, no Brasil, mesmo com maior veiculação das informações sobre os benefícios e a importância da prática de atividade física, o número de idosos que se exercitam regularmente ainda é pequeno. Segundo relatório do Sistema de Vigilância de Fatores de Risco e Proteção para Doenças Crônicas por Inquérito Telefônico (Vigitel), 22,2\% das pessoas com 65 anos ou mais praticam atividades físicas no tempo livre; $4,1 \%$ são ativas no deslocamento e 32,3\% são inativas fisicamente (BRASIL, 2012). Isso pode ser explicado por alguns fatores como: falta de interesse e de acesso; atitudes e crenças negativas sobre exercícios físicos; inexistência de suporte social; características ambientais inadequadas, como a ausência de espaços adequados, a falta de iluminação, a insegurança, entre outros (CORSEUIL et al., 2011; SALVADOR et al., 2010; SALVADOR et al., 2009; REICHERT, 2004).

A influência do ambiente, as barreiras, a adoção, permanência e motivação para a prática de atividade física têm sido foco de pesquisas envolvendo idosos (GIEHL et al., 2012; MEURER et al., 2011; EIRAS et al., 2010; REICHERT, 2004). Além desses aspectos, é relevante analisar e compreender os motivos de adoção e de permanência da população idosa em programas esportivos. Deve-se considerar que a literatura sobre a prática esportiva para idosos ainda é incipiente, e que a presente investigação possibilitará discussões e reflexões sobre como intervir e aumentar a participação desse grupo populacional em esportes, em especial, o voleibol.

Diante disso, o objetivo do presente estudo foi analisar o significado da prática do voleibol para idosos, procurando identificar os motivos de adoção e de permanência, bem como os procedimentos metodológicos utilizados para assegurar a participação efetiva em um programa realizado no âmbito da extensão universitária.

\section{Método}

Participaram deste estudo 11 idosos (oito mulheres e três homens) praticantes de voleibol, com idades variando de 60 a 78 anos, e um acadêmico (21 anos), cursando a quinta fase de Educação Física pela Universidade Federal de Santa Catarina (UFSC), que é o bolsista responsável pelas aulas de voleibol desenvolvidas no "Programa de Atividade Física e Dança Folclórica da Terceira Idade do Centro de Desportos - CDS/UFSC". 
Para a coleta das informações, foi aplicada uma entrevista semiestruturada e um questionário contendo questões dissertativas. A entrevista foi realizada com o acadêmico de Educação Física em um único dia. Para registrar o seu relato, utilizou-se um gravador digital. A entrevista foi composta de 15 questões que contemplavam os seguintes temas: características do programa de voleibol (objetivos, infraestrutura, número de alunos, horários, frequência semanal); conteúdos e estratégias (metodologia de ensino, relação professor-aluno, motivos de adoção e de permanência, desistência); avaliação (satisfação dos alunos e benefícios observados, desenvolvimento das aulas). Posteriormente, a entrevista foi transcrita na íntegra, tendo a aprovação do entrevistado.

Para os idosos, foi aplicado um questionário contendo três questões dissertativas: “O que o voleibol significa para você?", "Quais os motivos que o levaram a ingressar no programa de voleibol?", "Quais os motivos que o levam a permanecer no programa de voleibol?". O registro das respostas foi realizado pelos próprios idosos (quando observada a capacidade de registro) ou pelos pesquisadores.

Além disso, foi realizada análise documental do relatório de extensão do referido programa (FERNEDA et al., 2005). Este documento apresenta o resgate histórico dele, além de destacar a criação de atividades com bola para os idosos.

Os dados coletados foram analisados e interpretados por meio da técnica de Análise de Conteúdo (BARDIN, 1977), visando a criação de categorias e a construção de unidades de significado. Destaca-se que os nomes dos participantes foram alterados, na apresentação dos resultados, para preservar seu anonimato.

Este estudo atendeu a todos os princípios éticos e foi aprovado pelo Comitê de Ética envolvendo Seres Humanos da Universidade Federal de Santa Catarina, sob o protocolo no 205/09.

\section{Resultados e discussão}

Para a apresentação dos resultados, destaca-se que após análise e interpretação das informações foram criadas as seguintes categorias: contextualização do surgimento da modalidade voleibol para idosos e características do programa desenvolvido; significado do voleibol para os idosos; motivos da adoção; motivos da permanência e estratégias metodológicas, conforme apresentadas a seguir.

Contextualização do surgimento da modalidade voleibol para idosos e características atuais do programa

O "Programa de Atividade Física e Dança Folclórica da Terceira Idade do Centro de Desportos - CDS/UFSC" é desenvolvido no âmbito da extensão universitária da UFSC, desde 1985. Esse foi o segundo programa de atividade física destinado aos idosos no Brasil, iniciando com cinco idosas praticando ginástica (MAZO, LOPES e BENEDETTI, 2009). Com a evolução das atividades do programa de extensão, o voleibol surge em 1987, no contexto do desenvolvimento das atividades com bola. Porém, essa não era uma atividade que motivava a participação dos idosos, sendo desativada um ano depois, devido à pouca adesão a essa prática (FERNEDA et al., 2005).

Pensar a Prática, Goiânia, v. 17, n. 4, out./dez. 2014 
A desativação do voleibol nesse período pode ser compreendida pela resistência à prática de atividade física e pela falta de contato da população idosa com o esporte coletivo, em especial as mulheres. Vale ressaltar ainda que, para essa geração, não era comum essa prática como lazer. Além disso, para entender tal resistência, deve-se considerar o modo de vida do ilhéu catarinense e o contexto sociocultural da colonização açoriana (FERNEDA et al., 2005). Portanto, considerando tais aspectos, a ampliação e a expansão desse programa de extensão aconteceram de forma lenta e gradativa.

O retorno do voleibol nesse programa ocorreu no ano de 2000, devido ao êxito e ao entusiasmo dos idosos que participaram do I Jogos de Integração do Idoso (JIIDO). Assim, há 11 anos é desenvolvida essa modalidade, sendo que esse grupo de praticantes participa desde 2000 das diversas etapas do JIIDO e dos Jogos Abertos da Terceira Idade (JASTI), que ocorrem anualmente no estado de Santa Catarina.

Em relação aos idosos participantes desta investigação, a média de idade foi de 69 anos $(\mathrm{dp}=4,8)$, sendo a maioria casada e com baixa escolaridade. $O$ tempo de participação dos idosos na prática do voleibol variou de dois a 11 anos nesse programa, e eles não tinham experiência prévia com esse esporte. $\mathrm{O}$ bolsista responsável pelo desenvolvimento das aulas foi atleta de voleibol durante nove anos em uma equipe de rendimento de Florianópolis, realizou estágio de observação durante seis meses e há um ano desenvolvia as aulas de voleibol para os idosos do programa.

As aulas de voleibol eram oferecidas três vezes por semana, com duração de duas horas por encontro. Em relação à infraestrutura, a quadra era coberta, porém o piso não era adequado para a prática da modalidade e a luminosidade era baixa, podendo dificultar a visualização da bola. Segundo o acadêmico bolsista, os materiais utilizados eram considerados de qualidade. Os conteúdos desenvolvidos nas aulas envolveram aspectos técnicos e táticos, regras e o histórico do esporte. Dentre as estratégias metodológicas realizadas podem ser destacadas: atividades individuais, em duplas e em grupo; atividades envolvendo aspectos lúdicos; situações de jogo envolvendo os diferentes fundamentos; contextualização da criação das regras do voleibol. De acordo com o acadêmico bolsista, a relação entre o professor e o grupo de praticantes era de amizade, respeito e cumplicidade.

Significado do voleibol para os idosos

Para os idosos participantes do estudo, o significado da prática do voleibol estava vinculado a fatores como socialização; alegria, prazer e satisfação; saúde; disposição e bem-estar; esporte preferido; aceitar limitações; ocupação do tempo livre. Os três primeiros citados foram os mais recorrentes na fala dos participantes, como apresentado a seguir:

$\mathrm{O}$ vôlei significa a oportunidade de me exercitar com prazer. Fazendo amigos e ocupando meu tempo ocioso com satisfação (José, 67 anos).

Além de ser meu esporte preferido, significa para mim: alegria, estar com os amigos, ficar em forma, fazer exercícios, sair de casa, receber elogios, críticas [...] (Joana, 68 anos).

Pensar a Prática, Goiânia, v. 17, n. 4, out./dez. 2014 
Meus movimentos físicos, abaixar, correr, levantar, em nada tenho dificuldade graças ao vôlei, que pratico há muitos anos. Também a parte psicológica, faz muito bem para cabeça. Quando estou triste, penso que no outro dia vou jogar vôlei, o astral muda, sem falar nas amizades que fazemos através desses momentos que jogamos (Sônia, 74 anos).

Esses relatos permitem conjecturar que o significado do esporte para os idosos está atrelado à percepção dos benefícios físicos, psicológicos e sociais da prática esportiva, tais como a interação com outras pessoas, a realização pessoal, a melhora das aptidões funcionais, dentre outros.

Foi possível verificar também que, para alguns participantes, além dos benefícios acima destacados, outros fatores foram referidos como sendo relevantes e que para eles estão inter-relacionados, como a presença da alegria e do prazer em construir amizades, a capacidade de realizar os fundamentos do esporte e de aceitar as suas limitações. Destaca-se que esses aspectos foram mais peculiares nas falas das mulheres.

Um crescimento! Uma forma de trabalhar em equipe, um aprendizado constante onde se verifica a aceitação dos erros dos outros e as nossas próprias falhas, não só na parte física [...], além de ser um grande prazer praticar esse esporte (Abadia, 69 anos).

Além disso, o significado da prática esportiva mostrou-se relacionado à capacidade de superação das barreiras, em especial as físicas, decorrentes do processo de envelhecimento.

Meu objetivo maior na vida é estar aqui jogando vôlei e o que faço melhor. É uma honra, não é pra qualquer um (Sebastiana, 78 anos).

Os resultados obtidos corroboram parcialmente o que foi observado na pesquisa realizada com veteranos jogadores de basquete da cidade de Rio Grande, no Rio Grande do Sul (SILVEIRA; ROSA, 2010). Segundo as autoras, o significado da prática do basquetebol para os idosos remete ao jogo, destacando o equilíbrio das partidas e a vontade de vencer, bem como as relações sociais e esportivas intergeracional que ocorre entre os jogadores mais velhos com os jovens (SILVEIRA; ROSA, 2010). No presente estudo, a vontade de vencer não foi identificada como unidade de significado. Todavia, o aspecto positivo das relações sociais e o prazer pelo jogo mostram-se relevantes.

\section{Motivos de adoção do voleibol}

Dentre os motivos relatados pelos idosos para adoção do programa, destacam-se as questões que apareceram com mais frequência: o gosto pelo esporte, o convite de amigos ou cônjuge, a socialização, a saúde, a ocupação do tempo livre e a indicação médica.

[...] Por causa de meu problema de saúde [...] (Osvaldo, 66 anos).

Precisava voltar a praticar um esporte (José, 67 anos). 
A prática de um esporte. Fazer amigos (Joana, 68 anos).

Gosto pela atividade (Marta, 69 anos).

Motivação da esposa (Ś́lvio, 73 anos).

Os resultados encontrados diferem parcialmente da literatura, quando considerado os motivos de adoção citados pelos idosos. Porém, deve-se ressaltar que esses estudos (EIRAS et al. 2010; CARDOSO et al., 2008; CERRI; SIMÕES, 2007) envolveram modalidades que têm características diferentes das atividades esportivas (por exemplo: disputa entre equipes, luta indireta pela bola, dentre outras), limitando a comparação dos resultados. No estudo de Eiras e col. (2010), realizado com idosos praticantes de ginástica e caminhada, foi observado que a manutenção e/ou a promoção da saúde física foram os principais motivos para adoção. Já nas pesquisas envolvendo idosos praticantes de ginástica (CARDOSO et al., 2008) e de hidroginástica (CERRI; SIMÕES, 2007), a indicação médica foi o principal motivo.

Apesar de a busca pela saúde estar presente entre os achados dessa investigação, ressaltando a importância da melhora da aptidão e da capacidade funcional na vida desses idosos, esse aspecto é citado em menor frequência. A indicação médica foi citada somente por um idoso e esse fato pode ser compreendido pela prática clínica, em que é observada a orientação de atividades físicas de baixo impacto para essa população, como a hidroginástica e a caminhada.

O gosto pelo esporte foi apontado como o motivo mais frequente, indicando superação, mesmo que de forma parcial, da falta de contato dessa geração com o voleibol. Conforme já destacado anteriormente, há 23 anos essa modalidade foi desativada desse programa de extensão universitária, devido à baixa adoção (FERNEDA et al., 2005). Além da consolidação do voleibol no programa, é possível verificar que os idosos buscam esse esporte porque se identificam com ele (apesar de não terem tido experiência anterior) e/ou porque gostam de esporte. A aproximação com o voleibol pode ser explicada pela sua popularização no Brasil, em decorrência das medalhas olímpicas conquistadas, dos campeonatos nacionais e estaduais, da transmissão dos jogos na TV aberta, entre outros (CBV, 2013a). Também podem ser citados alguns fatores que contribuíram para essa popularização, como o aumento do número de ofertas da prática esportiva para idosos, nos últimos anos, por instituições como SESC, projetos de extensão universitária e projetos municipais.

Outrossim, a prática do voleibol pelos idosos brasileiros remete ao contexto histórico da criação desse esporte pela Associação Cristã de Moços (ACM) dos Estados Unidos. O voleibol foi criado como alternativa de um esporte menos fatigante para os associados mais velhos da ACM (CBV, 2013c). Devem ser consideradas as características e as especificidades do voleibol, ou seja, luta indireta na disputa e manipulação da bola em planos comuns à vida cotidiana, entre outras, desmistificando-o como um esporte de rigor técnico e tático, que requer exímio gesto motor e habilidades físicas, como se observa na prática competitiva de alto rendimento.

Pensar a Prática, Goiânia, v. 17, n. 4, out./dez. 2014 
Na percepção do acadêmico bolsista, responsável pelo desenvolvimento das aulas, o motivo mais importante para a adoção também foi o gosto pelo esporte. Destaca-se ainda, que a experiência esportiva anterior de alguns idosos deve ser considerada.

[...] a maior parte deles gosta de esporte ou praticou esporte quando era mais jovem.

[...] Por exemplo, tem um que era jogador de futebol e entrou depois para o vôlei.

[...] o público que gosta mesmo de esporte, [...] já praticou algum esporte durante outros períodos de sua vida (Tiago, 21 anos)

Em consonância, Pastre (2006) salienta que ex-atletas podem buscar outro esporte de menor impacto, visando benefícios para a saúde. Isso é observado no presente estudo, devido à participação de um ex-atleta de futebol.

\section{Motivos da permanência no voleibol}

Em relação aos motivos elencados pelos idosos para a permanência no programa, o gosto pela modalidade e por esportes, a socialização, a saúde e o bem-estar foram os mais citados. A atuação do responsável pelo desenvolvimento das aulas foi citada uma vez.

Porque estou gostando (Osvaldo, 66 anos).

Gosto muito, ter saúde sempre (Sebastiana, 78 anos).

Faz muito bem, [...] mais energia e [...] amigos (Margarida, 68 anos).

Gosto da atividade e [...] amizades (Sônia, 74 anos).

O bom relacionamento com amigos [...] (Joana, 68 anos).

Saúde, bem-estar, [...] (Lídia, 73 anos).

Na percepção do acadêmico bolsista, o gosto pela modalidade e por esportes também foi um motivo que auxiliou na permanência dos idosos no programa.

[...] gostam daquilo que fazem [...].

É uma coisa que eles gostam de fazer, eles sentem [...] vivos [...], por realizar aquelas atividades (Tiago, 21 anos)

Além disso, o acadêmico bolsista destacou aspectos referentes à cooperação, aos sentimentos de prazer e diversão, bem como a percepção de fazer parte de um grupo.

[...] primeiro tem o grupo [...], porque é uma atividade prazerosa para eles. Imagino que seja principalmente por isso [...].

[...] um grupo muito forte. Eles se ajudam muito [...].

$[\ldots]$ se sentem importantes naquele grupo [...].

[...] ele ajudava o outro, ria, batia palma quando o outro acertava [...]

(Tiago, 21 anos)

Pensar a Prática, Goiânia, v. 17, n. 4, out./dez. 2014 
Tais resultados estão em consonância com a literatura, sendo que o gosto pela atividade (EIRAS et al., 2010; CARDOSO et al.; 2008), o prazer (MEURER et al., 2011), o bem-estar (CARDOSO et al.; 2008) e a socialização (EIRAS et al., 2010; CERRI; SIMÕES, 2007) foram aspectos evidenciados em outras investigações com idosos realizadas com a ginástica, a hidroginástica e a caminhada.

Dessa forma, os motivos para a permanência nas atividades de voleibol assemelham-se às demais atividades físicas e estão relacionadas tanto aos motivos extrínsecos (socialização) quanto aos intrínsecos (prazer, bem-estar, gosto pela modalidade, percepção de fazer parte de um grupo, saúde) (MEURER et al., 2011; EIRAS et al., 2010).

Por ser uma atividade realizada em equipe, o voleibol estimula a socialização, bem como a cooperação na busca da solução de problemas, fazendo com que o idoso aprenda com suas limitações e com as diferenças individuais observadas no restante da equipe (PREFEITURA MUNICIPAL DE FLORIANÓPOLIS, 2009). Além disso, o jogo só se desenvolve com a existência da equipe oponente, sinalizando a importância de todos para o grupo, e favorecendo a percepção de estarem inseridos, de fazerem parte daquele grupo. Destaca-se que os sentimentos de prazer, alegria e diversão citados pelos participantes estão relacionados às trocas de bolas realizadas entre as duas equipes, às jogadas realizadas, ao tempo que a bola ficou no ar, à bola que foi defendida, ou seja, o ponto a ser marcado não é o único objetivo do jogo de voleibol para esses idosos. Acredita-se que a ressignificação do objetivo do esporte é um aspecto que contribui positivamente para a permanência desses na modalidade.

Vale ressaltar, ainda, o baixo número de desistências. No último ano, somente uma idosa deixou de participar do programa devido a uma lesão, sendo que essa não ocorreu durante o desenvolvimento das aulas de voleibol.

\section{Estratégias metodológicas}

Em relação às estratégias metodológicas utilizadas para que os idosos permaneçam no programa de voleibol, foi destacada a realização de atividades e de exercícios que eles gostavam de executar (em especial, o jogo), bem como a forma de organização dos grupos para o desenvolvimento das atividades e o controle de situações adversas.

[...] o jogo, que é o que eles mais gostam [...].

[...] quando vejo que [...] não tá dando nada certo, paro o jogo, peço para eles tomarem uma água [...], ficam naquela agonia, afobados [...] (Tiago, 21 anos)

Conforme destacam Barroso e Darido (2010), o voleibol apresenta em sua essência o jogo, que socioculturalmente motiva e estimula as pessoas. No caso dos idosos, esse aspecto não é diferente. $\mathrm{O}$ jogo foi destacado como fator motivador, proporcionando o desenvolvimento da prática do voleibol.

De acordo com o acadêmico bolsista, durante o jogo também foram ensinadas questões importantes, como os aspectos técnicos e táticos, bem como a explicação das regras do esporte. 
[...] vou fazendo durante o jogo as modificações e [...] trabalhando alguns aspectos técnicos e táticos durante a prática do jogo mesmo, em si. [...] ensinar os aspectos técnicos em situações de jogo. Porque às vezes eles até conseguiam fazer uma manchete na parede, mas chegava na situação de jogo, eles não conseguiam adaptar para aquela situação (Tiago, 21 anos)

Entende-se que essa é uma estratégia importante, pois são utilizadas as próprias situações que ocorrem durante o jogo para a efetivação do processo ensino-aprendizagem dos fundamentos, dos aspectos táticos e das regras. Graça e Mesquita (2002) destacam a necessidade do ensino das habilidades complexas que requerem coordenação e ajustamento temporal, devendo ser privilegiadas as situações que apresentem problemas semelhantes aos que surgem em situação de jogo.

Para os idosos, assim como para os demais grupos etários, o processo ensinoaprendizagem dos esportes coletivos deve utilizar estilos de ensino diferentes daqueles centrados no professor. Ou seja, a tomada de decisões pode ser iniciada e realizada pelo aprendiz, sem esperar que o comando inicial seja dado pelo professor. Para tanto, deve ser observada a individualidade biológica, o nível de atividade física e a aptidão funcional do idoso. Conforme destaca Safons e Pereira (2007), para alunos mais treinados é possível desenvolver atividades mais dinâmicas e com maior exigência de controle motor, pois estes idosos conseguem perceber a intensidade do esforço, respeitando seus limites. Para o grupo de iniciantes ou indivíduos com baixo nível de atividade física, faz-se necessário o desenvolvimento de atividades menos dinâmicas, que permitam maior controle sobre a intensidade (SAFONS; PEREIRA, 2007).

A forma de organização dos idosos para a realização das atividades também deve ser considerada. As atividades eram realizadas de forma individual, em duplas ou em pequenos grupos, sendo que, nessa divisão, tenta-se separar os casais ou os parentes. Segundo o acadêmico bolsista, há uma relação de dependência para a realização das atividades de grupo. Assim, se o idoso não tiver respeito pelas limitações do outro, o erro acaba sendo um motivo de desentendimento. E, para casais e parentes, a intimidade pode contribuir para o surgimento de situações de desrespeito, fazendo com que as constantes reclamações sobre os erros se tornem um fator desmotivante para a prática de voleibol.

[...] por exemplo, os casais. Não colocar o casal junto [...], porque isso gera muito atrito, briga. [...] é super importante não deixar que isso atrapalhe o andamento [...] porque eles já estão o dia inteiro juntos, porque ... tem que ficar um do lado do outro ali... Então com outra pessoa tem coisa que ele não vai fazer e com a esposa, por já ter uma relação de anos, ele às vezes toma uma intimidade que não é adequada, [...] (Tiago, 21 anos).

A satisfação dos idosos é outro aspecto que merece destaque, uma vez que está atrelado aos resultados positivos das estratégias metodológicas utilizadas. Para o acadêmico, o bem-estar, a alegria, o prazer e a diversão contribuíram positivamente para a permanência dos idosos no programa de voleibol. 
[...] Se eles não estiverem se divertindo, eles não voltam mais ali. Se não for uma coisa prazerosa, eles não vão vir mais jogar. [....].

[...] eu vejo nos outros também muita alegria quando conseguem acertar uma bola, que faz uma jogada interessante, bonita [...] alegria, sai contando para os outros, rindo [...]. É uma situação onde eles se sentem soltos [...]. Eu vejo eles como se estivessem ali brincando, brincando e se divertindo [...].

[...] ele retomou aquela parte que é a curtição, que é a parte do jogo, do lúdico, do brincar, do se divertir (Tiago, 21 anos).

A presença do prazer, da alegria e da diversão como motivos facilitadores da permanência pode ser identificada no exemplo do caso de uma idosa de 78 anos.

[...] tem uma com 78 anos [...], uma pessoa com 78 anos pegar dois ônibus para vir aqui três vezes por semana, às oito horas da manhã [...]. Então, eu acho que ela tem que sentir muito prazer no que ela tá fazendo, senão ela não viria [...] (Tiago, 21 anos).

Corroborando o relato dos idosos, outro aspecto evidenciado pelo acadêmico diz respeito aos benefícios físicos, sociais e psicológicos proporcionados pela prática do voleibol. Dentre estes, foram elencados a melhoria da saúde, da aptidão e da capacidade funcional, além das melhorias sociais e psicológicas.

[...] uma falou que chegou a parar a dor nas costas dela, que ela sentia $[\ldots]$.

[...] tem esse aspecto da aptidão física, que seria mais da flexibilidade, da velocidade de reação, que é proporcionada uma melhoria da velocidade, também a força explosiva deles [...].

Se você vê caminhando, eles se virando de um lado para outro, levantam e sentam no colchonete sem nenhum problema [...].

[...] e também os aspectos emocionais e sociais. Tem uma ali que ela tem um problema [...]. Aí ela chega, um abraça, outro beija, outro a incomoda. Ela vai, faz um ponto, é aquela gritaria, aí eles vão abraçam ela. [...] É o momento de fuga dela, da realidade que ela vive [...] é o momento que ela consegue se libertar, soltar, brincar (Tiago, 21 anos).

Outrossim, além dos aspectos observados nesse grupo de idosos, espera-se oportunizar reflexão sobre novas estratégias metodológicas para o ensino do voleibol tanto para a população que ora envelhece quanto para a atual geração envelhecida, considerando as diferenças e os contextos socioculturais, em que foram e estão inseridas.

\section{Considerações finais}

Por ser um estudo realizado com amostra intencional e que envolveu pequeno número de participantes, os resultados não permitem fazer inferências. Entretanto, pela lacuna existente na literatura sobre a prática do voleibol por pessoas idosas, os resultados encontrados oportunizam melhor entendimento da busca dessa população pela prática es- 
portiva, além de possibilitar reflexão sobre os motivos da permanência desse grupo etário em programas de voleibol.

A socialização, a alegria, a disposição, o bem-estar e a saúde foram as categorias mais relatadas pelos participantes para indicar o significado do voleibol. O gosto pela modalidade foi o motivo mais frequente tanto para a adoção quanto para a permanência dos idosos no programa. Esses aspectos foram gerados pelas características e especificidades da modalidade, pelo fator motivador proporcionado pelo jogo (importante estratégia metodológica observada no programa para assegurar a participação efetiva), bem como pela ressignificação realizada pelos idosos para o objetivo do esporte. Tal ressignificação se distancia do esporte de rigor técnico, tático e físico que se tem observado na prática competitiva de alto rendimento, e se aproxima do objetivo da criação do voleibol em 1895, que foi idealizado como alternativa de um esporte menos fatigante para os associados mais velhos da Associação Cristã de Moços.

Sugere-se que mais estudos (envolvendo maior número de pessoas; análise dos dados por gênero e/ou grupos etários, entre outros) sejam realizados, contribuindo para a produção do conhecimento, além de apresentar outras possibilidades de como intervir, aumentar e assegurar a participação efetiva desse segmento populacional em programas esportivos.

\title{
SIGNIFICANCE OF SPORT PRACTICE OF VOLLEYBALL: CASE STUDY FOR OLDER PEOPLE
}

\begin{abstract}
This qualitative study aimed to analyze the significance and adoption and permanence of sport practice of volleyball for older people in the university extension program. The data were collected through documental analysis, semi-structured interview and questionnaire, performed by content analysis. The meaning of volleyball is related to socialization, mood and well-being, health. Liking sport was the most cited reason for adherence and permanence. The categories analyzed showed interrelated to perception of physical, psychological and social benefits of sport practice. Moreover, it was observed a new definition in the sport goal by older people and play volleyball provided a motivating factor for the development it.
\end{abstract}

Keywords: Volleyball. Aged. Aging.

\section{SIGNIFICADO DE LA PRÁCTICA DEPORTIVA DEL VOLEIBOL: ESTUDIO DE CASO PARA ANCIANOS}

\section{Resumen}

El objetivo de este estúdio fue analizar el significado y las razones de su adopción y permanencia en la práctica del voleibol para ancianos en un programa de extensión universitaria. Los datos fueron obtenidos a través de análisis documental, entrevista semi-estructurada y un cuestionario conteniendo preguntas de ensayo, que fueron analizadas e interpretadas por medio de análisis de contenido. Se pudo comprobar que el significado de voleibol está ligada a la socialización, el estado de ánimo y el bienestar, la salud. El gusto por la práctica de voleibol es la razón más citada para la adopción y mantenimiento de los ancianos en el programa. Las categorías analizadas mostraron relacionados entre sí y vinculados a los beneficios percibidos de violencia física, psicológica y social. Por otro lado, se observó que los ancianos dieron un nuevo significado a los 
objetivos del deporte y, el juego como estrategia metodológica, resultó ser un factor de motivación para el desarrollo del voleibol.

Palabras clave: Voleibol. Anciano. Envejecimiento.

\section{Referências}

BARDIN, L. Análise de conteúdo. Rio de Janeiro: Edições 70, 1977.

BARROSO, A. L. R.; DARIDO, S. C. Voleibol escolar: uma proposta de ensino nas dimensões conceitual, procedimental e atitudinal do conteúdo. Revista Brasileira de Educação Física Esporte, São Paulo, v. 24, n. 2, p. 179-194, 2010.

BOJIKIAN, J. C. M. Ensinando voleibol. 3. ed. São Paulo: Phorte, 2005.

BRASIL. Ministério da Saúde. Secretaria de Vigilância em Saúde. Secretaria de Gestão Estratégica e Participativa. Vigitel Brasil 2011: vigilância de fatores de risco e proteção para doenças crônicas por inquérito telefônico. Brasília: Ministério da Saúde, 2012.

CARDOSO, A. S.; BORGES, L. J.; MAZO, G. Z.; BENEDETTI, T. R. B.; KUHNEN, A. P. Fatores influentes na desistência de idosos em um programa de exercício físico. Movimento, Porto Alegre, v. 14, n. 1, p. 225-239, 2008.

CERRI, A. de S.; SIMÕES, R. Hidroginástica e idosos: por que eles praticam? Movimento, Porto Alegre, v. 13, n. 1, p. 81-92, 2007.

CONFEDERAÇÃO BRASILEIRA DE VOLEIBOL (CBV). História do vôlei brasileiro. 2013a. Disponível em: <http://www.cbv.com.br/v1/institucional/histbrasileiro.asp $>$. Acesso em: 23 maio 2013.

CONFEDERAÇÃO BRASILEIRA DE VOLEIBOL (CBV). Vôlei Master 2012. 2013b. Disponível em: <http://www.cbv.com.br/v1/voleimaster2012/master.asp>. Acesso em: 23 maio 2013.

CONFEDERAÇÃO BRASILEIRA DE VOLEIBOL (CBV). História do voleibol. 2013c. Disponível em: <http://www.cbv.com.br/v1/institucional/histvolei.asp>. Acesso em: 23 maio de 2013.

COURSEUIL, M. W.; SCHNEIDER, I. J.; SILVA, D. A. S.; COSTA, F. F.; SILVA, K. S.; BORGES, L. J.; D'ORSI, E. Perception of environmental obstacles to commuting physical activity in Brazilian elderly. Preventive Medicine, San Diego, v. 53, p. 289-292, 2011.

EIRAS, S. B.; SILVA, W. H. A.; SOUZA, D. L.; VENDRUSCOLO, R. Fatores de adesão e manutenção da prática de atividade física por parte de idosos. Revista Brasileira de Ciência e Esporte, Campinas, v. 31, n. 2, p. 75-89, 2010. 
FERNEDA, F.; SEBASTINI, F.; GIUMBELLI, I. C.; MARQUES, P.; LOPES, M. A.; BENEDETTI, T. R. B. Programa de atividade física para a terceira idade da UFSC: 20 anos a serviço da comunidade. Extensio: Revista Eletrônica de Extensão, Florianópolis, n. 3, p. 3-37, 2005. Disponível em: <http://www.extensio.ufsc.br/>. Acesso em: 20 ago. 2011.

GIEHL, M. W. C.; SCHNEIDER, I. J. C.; CORSEUIL, H. X.; BENEDETTI, T. R. B.; D'ORSI, E. Atividade física e percepção do ambiente em idosos: estudo populacional em Florianópolis. Revista de Saúde Pública, São Paulo, v. 46, n. 3, p. 516-525, 2012.

GRAÇA, A.; MESQUITA, I. A investigação sobre o ensino dos jogos desportivos: ensinar e aprender as habilidades básicas do jogo. Revista Portuguesa de Ciências do Desporto, Porto, v. 2, n. 5, p. 67-79, 2002.

MAZO, G. Z.; LOPES, M. A.; BENEDETTI, T. R. B. Atividade física e o idoso: concepção gerontológica. 3. ed. Porto Alegre: Sulina, 2009.

MEURER, S. T.; BENEDETTI, T. R. B.; MAZO, G. Z. Teoria da autodeterminação: compreensão dos fatores motivacionais e autoestima de idosos praticantes de exercícios físicos. Revista Brasileira de Atividade Física e Saúde, Londrina, v. 16, n. 1, p. 18-24, 2011.

PASTRE, T. G. F. L. O basquetebol veterano no Paraná: a formação de grupos e instituições social. 2006. 126 p. Dissertação (Mestrado) - Programa de Pós-Graduação, Universidade Federal do Paraná, Curitiba, 2006.

PREFEITURA MUNICIPAL DE FLORIANÓPOLIS. Vôlei adaptado. 2009. Disponível em: $\quad<$ http://www.pmf.sc.gov.br/entidades/semas/index.php? pagina $=$ notpagina\&noti $=220>$. Acesso em: 15 ago. 2011 .

REICHERT, F. F. Barreiras à prática de atividades físicas: prevalência e fatores associados. 2004. 119 f. Dissertação (Mestrado) - Programa de Pós-Graduação em Epidemiologia, Universidade Federal de Pelotas, Pelotas, 2004.

SAFONS, M. P.; PEREIRA, M. de M. Princípios metodológicos da atividade física para idosos. Brasília: CREF/DF; FEF/UnB/Gepafi, 2007. 110 p.

SALVADOR, E. P.; REIS, R. de S.; FLORINDO, A. A. Practice of walking and its association with perceived environment among elderly Brazilians living in a region of low socioeconomic level. International Journal of Behavioral Nutrition and Physical Activity, London, n. 7, p. 1-7, 2010.

SALVADOR, E. P.; FLORINDO, A. A.; REIS, R. de S.; COSTA, E. F. Percepção do ambiente e prática de atividade física no lazer entre idosos. Revista de Saúde Pública, São Paulo, v. 43, n. 6, p. 972-980, 2009. 
SILVEIRA, R.; ROSA, S. M. da. Envelhecimento e esporte: um estudo sobre os basqueteiros veteranos da cidade do Rio Grande/RS. Caderno de Educação Física, Marechal Cândido Rondon, v. 9, n. 17, p. 57-66, 2010.

Recebido em: 20/11/2013

Revisado em: 06/10/2014

Aprovado em: 02/12/2014

Endereço para correspondência:

luceliajb@yahoo.com.br

Lucélia Justino Borges

Universidade Federal de Santa Catarina, Centro de Desportos - CDS.

Campus Universitário Reitor João David Ferreira Lima

Trindade

88040970 - Florianópolis, SC - Brasil 